\title{
High-density multicore fiber with heterogeneous core arrangement
}

Amma, Y.; Sasaki, Y.; Takenaga, K.; Matsuo, S.; Tu, J.; Saitoh, K.; Koshiba, M.; Morioka, Toshio; Miyamoto, $\mathbf{Y}$.

Published in:

Proceedings of the Optical Fiber Communications Conference and Exhibition 2015

Publication date:

2015

Document Version

Publisher's PDF, also known as Version of record

Link back to DTU Orbit

Citation (APA):

Amma, Y., Sasaki, Y., Takenaga, K., Matsuo, S., Tu, J., Saitoh, K., Koshiba, M., Morioka, T., \& Miyamoto, Y. (2015). High-density multicore fiber with heterogeneous core arrangement. In Proceedings of the Optical Fiber Communications Conference and Exhibition 2015 (pp. 1-3). IEEE.

\section{General rights}

Copyright and moral rights for the publications made accessible in the public portal are retained by the authors and/or other copyright owners and it is a condition of accessing publications that users recognise and abide by the legal requirements associated with these rights.

- Users may download and print one copy of any publication from the public portal for the purpose of private study or research.

- You may not further distribute the material or use it for any profit-making activity or commercial gain

- You may freely distribute the URL identifying the publication in the public portal 


\title{
High-density Multicore Fiber with Heterogeneous Core Arrangement
}

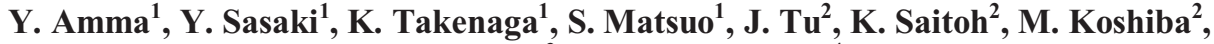 \\ T. Morioka ${ }^{3}$, and Y. Miyamoto ${ }^{4}$ \\ ${ }^{I}$ Optics and Electronics Laboratory, Fujikura Ltd. 1440, Mutsuzaki, Sakura, Chiba, 285-8550, Japan \\ E-mail: yoshimichi.amma@jp.fujikura.com \\ ${ }^{2}$ Graduate School of Information Science and Technology, Hokkaido University, Sapporo, Hokkaido, 060-0814, Japan \\ ${ }^{3}$ Department of Photonics Engineering, Technical University of Denmark, Kgs. Lyngby, 2800, Denmark \\ ${ }^{4}$ NTT Network Innovation Laboratories, NTT Corporation, Yokosuka, Kanagawa, 239-0847, Japan
}

\begin{abstract}
A 30-core fiber with heterogeneous cores that achieved large spatial multiplicity and low crosstalk of less than $-40 \mathrm{~dB}$ at $100 \mathrm{~km}$ was demonstrated. The correlation lengths were estimated to be more than $1 \mathrm{~m}$.

OCIS codes: (060.2270) Fiber characterization, (060.2280) Fiber design and fabrication
\end{abstract}

\section{Introduction}

A multicore fiber (MCF) is expected to serve as a more promising candidate to overcome the capacity limit of optical communication systems compared to the single mode fibers (SMFs). Transmission experiments over MCFs with high core counts of 12 and 19 have been demonstrated [1, 2]. It is difficult to improve the core count under the limitation of the cladding diameter [3] and achieve sufficient low crosstalk (XT) and moderate effective area $A_{\text {eff }}$ without any breakthrough in fiber design.

In this paper, we propose a 30-core fiber with heterogeneous cores [4]. The fiber involves four kinds of cores to achieve both large spatial multiplicity and low XT. The correlation length of the fiber is experimentally investigated.

\section{Correlation-length dependence of crosstalk}

The XT characteristics of quasi-homogeneous MCFs (QH-MCFs) have been investigated [5-7]. Figure 1 illustrates the XT behavior as a function of the bending radius $R$. If $R$ is smaller than $R_{\mathrm{pk}}$, defined by Eq. 1 in Fig. 1 [4], the XT of the QH-MCF is expressed as Eq. 2 in Fig. 1 [6]; we call the region an $R$-dominant region because XT strongly depends on $R$. If $R>R_{\mathrm{pk}}$, XT of this region is smaller than that of the $R$-dominant region, correlation length $d$ is a dominating parameter of XT as Eq. 3 in Fig. 1 [7] shows, and XT becomes small as $d$ becomes large. It was reported that $d$ of the QH-MCF was about $50 \mathrm{~mm}$ [7]. Nevertheless, the effect of $d$ of the heterogeneous MCF has been unclear so far.

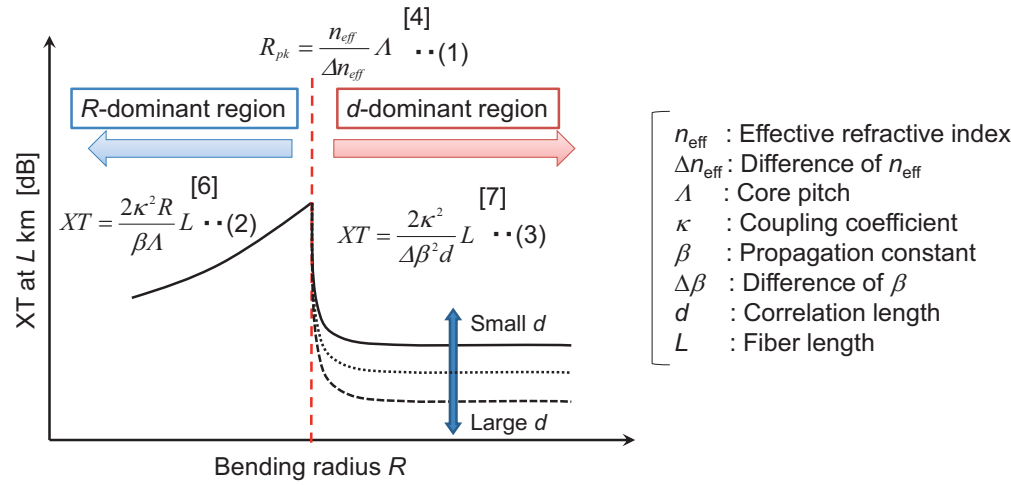

Fig. 1. Schematic of XT behavior as a function of bending radius $R$ taking correlation lengths $d$ as parameters.

\section{30-core fiber with heterogeneous core arrangement}

We designed and fabricated a 30-core fiber with four kinds of cores to evaluate $d$ of a heterogeneous MCF. Figures 2 (a) and (b) show the schematic structure and a cross-sectional view of a fabricated fiber, respectively. The design parameters of the four kinds of cores are summarized in Table 1. Cores 1, 2, and 3 are trench-assisted (TA) to reduce XT, and Core 4 is a step-index core with no trench cladding, as shown in Fig. 2 (c), to avoid the lengthening of the cutoff wavelength of cores that are surrounded by TA-cores [8]. $A_{\mathrm{eff}}$ of all cores were designed as $80 \mu^{2}$ although $n_{\mathrm{eff}} \mathrm{S}$ are heterogeneous [4]. Core pitch $\Lambda$ was $30 \mu \mathrm{m}$ and $\Delta n_{\mathrm{eff}}$ and $R_{\mathrm{pk}}$ between different combinations of cores are 


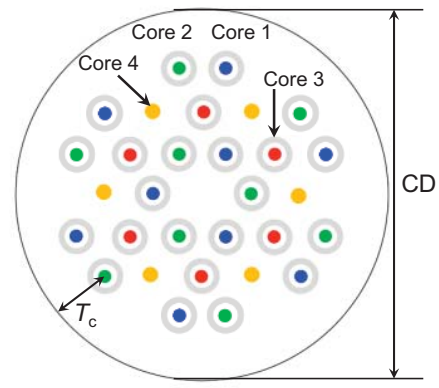

(a) Schematic structure

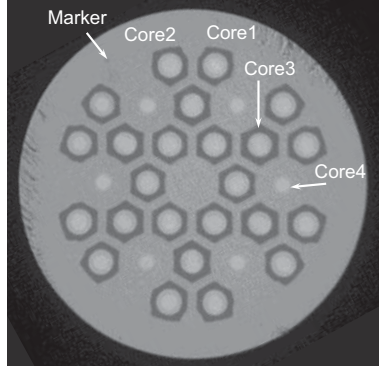

(b) Cross-sectional view

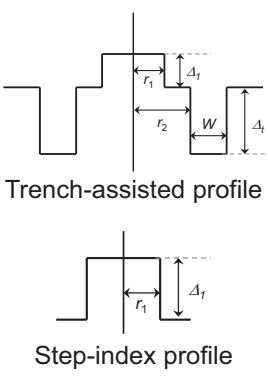

(c) Index profile of cores

Fig. 2. Schematic structure and cross-sectional view of a fabricated MCF.

Tab. 1. Design parameters of a fabricated fiber.

\begin{tabular}{|c|c|c|c|c|c|}
\hline & $r_{1}[\mu \mathrm{m}]$ & $\Delta_{1}[\%]$ & $r_{2} / r_{1}$ & $W / r_{1}$ & $A_{\text {eff }}^{2)}\left[\mu \mathrm{m}^{2}\right]$ \\
\hline Core $^{1)}$ & 4.76 & 0.338 & 1.7 & 1.0 & 80.2 \\
\hline Core 2 $^{1)}$ & 4.62 & 0.305 & 1.7 & 1.0 & 80.3 \\
\hline Core 3 $^{1)}$ & 4.47 & 0.273 & 1.7 & 1.2 & 80.2 \\
\hline Core 4 & 4.68 & 0.388 & - & - & 80.0 \\
\hline
\end{tabular}

\begin{tabular}{|c|c|c|}
\hline & $\Delta n_{\text {eff }}^{2)}$ & $R_{\mathrm{pk}}[\mathrm{mm}]$ \\
\hline Core 1-2 & 0.00051 & 86 \\
\hline Core 1-3 & 0.00100 & 44 \\
\hline Core 1-4 & 0.00063 & 69 \\
\hline Core 2-3 & 0.00050 & 88 \\
\hline Core 2-4 & 0.00113 & 38 \\
\hline Core 3-4 & 0.00163 & 27 \\
\hline
\end{tabular}

shown in Table 1. We evaluated $d$ for $\Delta n_{\mathrm{eff}}$ by selecting the core combination. The cladding diameter (CD) was 229 $\mu \mathrm{m}$. The outer cladding thickness $\left(T_{\mathrm{c}}\right)$ was $33.8 \mu \mathrm{m}$ in terms of excess loss due to a high-index coating [8].

We fabricated a 30-core fiber by the stack-and-draw method based on the design. Average $\Lambda$ was $29.7 \mu \mathrm{m}, \mathrm{CD}$ was $228 \mu \mathrm{m}$, and fiber length $L$ was $9.6 \mathrm{~km}$. Average $A_{\text {eff }}$ at $1.55 \mu \mathrm{m}$ was $77.3 \mu \mathrm{m}^{2}$ and cable cutoff wavelengths were less than $1.57 \mu \mathrm{m}$.

\section{Crosstalk characteristics of a fabricated fiber}

We measured XT using statistical measurements by sweeping the wavelength and a TA-SMF was used as the incident and receiving fiber to improve the dynamic range of XT to about $80 \mathrm{~dB}$ [6]. Figure 3 compares the simulated and measured XT of Core 1-2, Core 1-4, and Core 1-3 for $L=22 \mathrm{~m} . R$ dependence of XT was simulated for $d$ of $50 \mathrm{~mm}, 1 \mathrm{~m}, 10 \mathrm{~m}$, and $100 \mathrm{~m}$. We measured the XT of the freely-coiled fiber at $R$ of $140 \mathrm{~mm}, 70 \mathrm{~mm}$, and $35 \mathrm{~mm}$ to confirm the XT behavior at around $R_{\mathrm{pk}}$. Figure 3 demonstrates that the simulated XT and measured XT show good agreement over the $R$-dominant region of $R<R_{\mathrm{pk}}$. We cannot determine $d$ from Fig. 3 because XT at $R>$ $R_{\mathrm{pk}}$ was approximately $-80 \mathrm{~dB}$, which is close to the threshold of our measurement system.

The measured XT of the $9.6-\mathrm{km}$ fiber are plotted in Fig. 4. The simulated XT at $L=9.6 \mathrm{~km}$ for various $d \mathrm{~s}$ are also plotted. The fiber was wound on a spool of $R=155 \mathrm{~mm}$. Correlation lengths $d$ are estimated to about $1 \mathrm{~m}, 100$ $\mathrm{m}$, and $10 \mathrm{~m}$, respectively. Note that $d$ estimated from Fig.4 (c) involves uncertainty because the measured XT is close to the threshold of our measurement system. Figure 4 suggests that $d$ of the heterogeneous MCF are larger than that of the QH-MCF and depends on $\Delta n_{\text {eff }}$ between cores.

The fabricated MCF realized XT of less than $-50 \mathrm{~dB}$ at $L=$ about $10 \mathrm{~km}$. The $100-\mathrm{km}$ XT of the MCF is estimated to be less than $-40 \mathrm{~dB}$, realizing high-density transmission with a high-order modulation format [1].

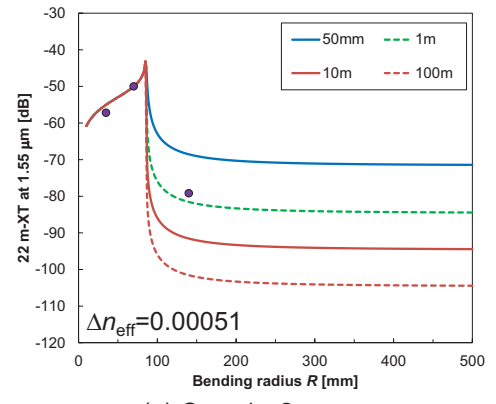

(a) Core 1 - 2

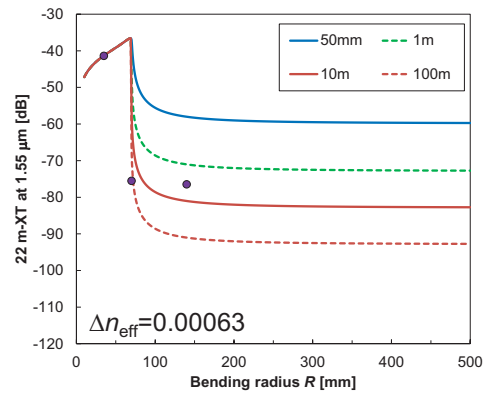

(b) Core 1 - 4

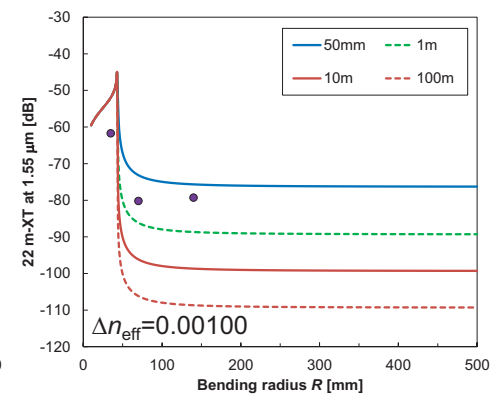

(c) Core 1 - 3

Fig. 3. Measured and calculated 22-m XT at $1.55 \mu \mathrm{m}$ for core combinations with different $\Delta n_{\text {eff. }}$ (Solid symbols: measured XT, Lines: calculated XT) 


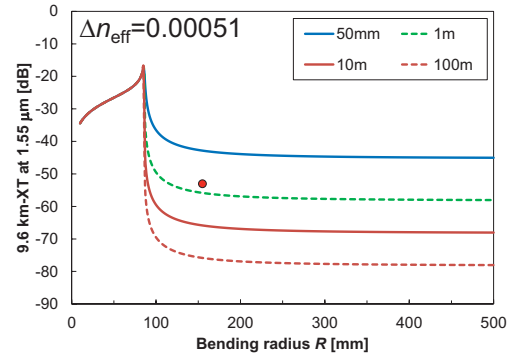

(a) Core 1 - 2

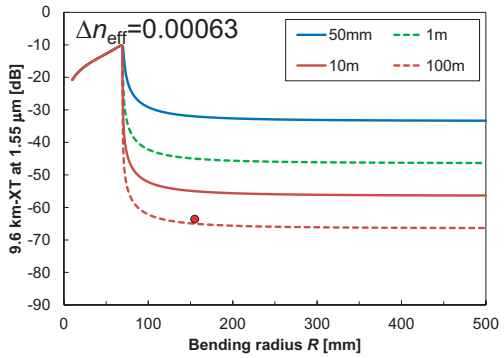

(b) Core1 - 4

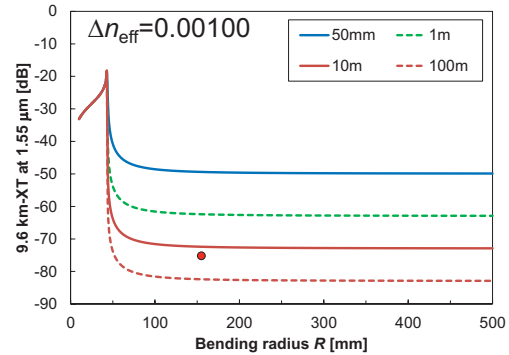

(c) Core 1 - 3

Fig. 4. Measured and calculated $9.6-\mathrm{km} \mathrm{XT}$ at $1.55 \mu \mathrm{m}$ for core combinations with different $\Delta n_{\text {eff. }}$.

(Solid symbols: measured XT, Lines: calculated XT)

\section{Spatial multiplicity of a fabricated fiber}

Figure 5 shows the spatial multiplicity and the worst XT at $L=100 \mathrm{~km}$, which is the total XT when all neighboring cores are excited, of the fabricated single-mode MCFs (SM-MCFs). Figures 5 (a) and (b) show the relative core multiplicity factor (RCMF), defined by Eq. 4 [8], and the core count $N$, respectively. The RCMF of the fabricated 30-core fiber is reached at about 9 with low worst-case XT of $-40 \mathrm{~dB}$ whereas that of the previous SM-MCFs was less than 7, and the core count of the 30-core fiber also greatly increases compared to that of the previous SM-MCFs.

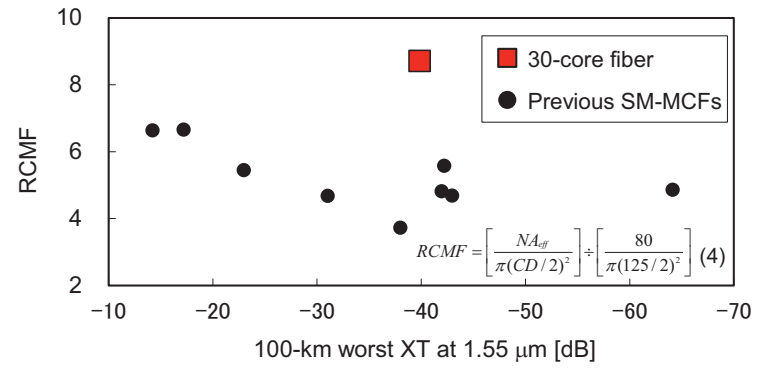

(a) RCMF

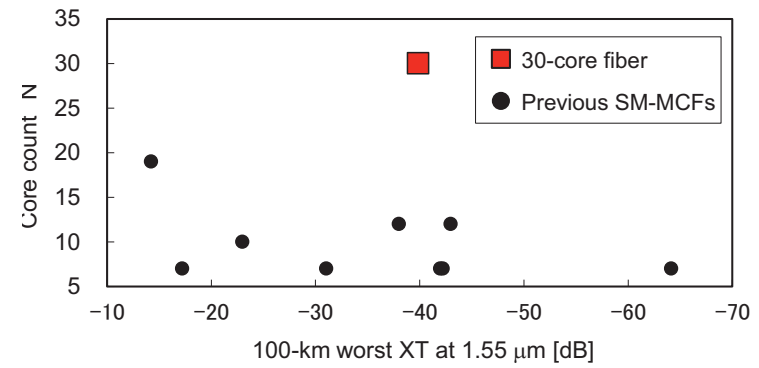

(b) Core count $N$

Fig. 5. Comparison of spatial multiplicity of fabricated single-mode MCFs.

\section{Conclusion}

We designed and fabricated a 30-core fiber with four types of cores to realize high-density core arrangement with low XT and investigated the correlation length between heterogeneous cores. The fabricated 30-core fiber achieved $A_{\text {eff }}$ of $\sim 80 \mu \mathrm{m}^{2}$ and low XT of less than $-50 \mathrm{~dB}$ at $9.6 \mathrm{~km}$ even though up to 30 cores were arranged in the limited cladding diameter of less than $230 \mu \mathrm{m}$, and correlation lengths were estimated to be more than $1 \mathrm{~m}$.

\section{Acknowledgement}

A part of this work is supported by the EU-Japan coordinated R\&D project on "Scalable And Flexible optical Architecture for Reconfigurable Infrastructure (SAFARI)" by the Ministry of Internal Affairs and Communications (MIC) of Japan and EC Horizon 2020.

\section{References}

[1] H. Takara et al., "1.01-Pb/s (12 SDM/222 WDM/456 Gb/s) crosstalk-managed transmission with 91.4-b/s/Hz aggregate spectral efficiency," ECOC 2012, Th.3.C.1, 2012.

[2] J. Sakaguchi et al., "19-core fiber transmission of 19x100x172-Gb/s SDM-WDM-PDM-QPSK signals at 305Tb/s," OFC/NFOEC 2012, PDP5C.1, 2012.

[3] S. Matsuo et al., "Large-effective-area ten-core fiber with cladding diameter of about $200 \mu \mathrm{m}$," Opt. Letters, vol. 36, no. 23, pp. 4626-4628, 2011.

[4] K. Saitoh et al., "Low-crosstalk multicore fibers for long-haul transmission,” SPIE 8284, 82840I, 2012.

[5] K. Takenaga et al., "An investigation on crosstalk in multi-core fibers by introducing random fluctuation along longitudinal direction," IEICE Trans. Commun., vol. E94-B, no. 2, pp. 409-416, 2011.

[6] T. Hayashi et al., "Characterization of crosstalk in ultra-low-crosstalk multi-core fiber," IEEE J. Lightwave Tech., vol. 30, no. 4, pp. 583-89, 2012.

[7] M. Koshiba et al., "Analytical expression of average power-coupling coefficients for estimating inter core crosstalk in multicore fibers," IEEE Photon. J., vol. 4, pp. 1987-1995, 2012.

[8] K. Takenaga et al., "A large effective area multi-core fiber with an optimized cladding thickness," Opt. Express, vol. 19, no. 26, pp. B543B550, 2011. 